\title{
RASTROS Y RESONANCIAS DANNUNZIANAS EN LA POESÍA DE LUGONES is
}

Alma Novella Marani, conocida crítica y profesora de la Universidad de La Plata, en su Tonos y motivos italianos en la literatura argentina ${ }^{1}$ coteja algunos pasajes poéticos de Lugones con otros de D'Annunzio evidenciando ciertos "rastros" y "resonancias" del italiano en el argentino. Intentaré aquí ampliar el cotejo, que me parece acertado, mediante un examen analítico (léxico, icónico y estilístico) de los pasajes correspondientes.

La propia Marani recuerda, entre otras cosas, que Lugones, al morir Darío, escribió un artículo, titulado "Rubén Darío", en la revista Buenos Aires (15/02/1899), en el cual se asombraba de que el nicaragüense hubiese sufrido la influencia de un poeta tan "retórico" y "decadente" como Gabrielle D'Annunzio. Lugones "no sospechaba, por lo visto, que en su conducta futura se verían repetidas actitudes muy cercanas a las del poeta de Pescara" 2 . Partió, pues, de una actitud de "desdén" ante los que llamaba "defectos abominables" pero él tampoco dejó de sufrir la influencia del vate abrucés. En cambio, José Ingenieros, amigo de Lugones, defendió en seguida a D'Annunzio en sendos artículos publicados en la revista porteña El Mercurio de América ${ }^{3}$. De todos modos, las obras de D'Annunzio acabaron por influir no sólo en Darío sino también en una serie de escritores argentinos más jóvenes, como Ángel Estrada, Leopoldo Díaz, Alfredo L. Bufano. El mismo uruguayo Horacio Quiroga, en uno de sus cuentos, "Los arrecifes de coral", muestra influencias dannunzianas bien precisas como lo ha señalado, desde hace tiempo, el conoci-

${ }^{1}$ La Plata, 1977, pp. 131 ss.

${ }^{2}$ Ibid., pp. 131-132.

${ }^{3}$ Aparecieron respectivamente en los números 2-3 (agosto-septiembre de 1888) y 8 (febrero de 1889). Cf. MARANI, op. cit., p. 134. 
do crítico compatriota suyo, Sergio Visca, al publicar sus Cartas Inéditas, Montevideo, 19594. Ya en Los crepúsculos del jardín de Lugones (1905) se pueden percibir "resonancias de las rimas dannunzianas" junto con "influjos ciertos -y muchas veces señalados-de Samain, de Verlaine, del Darío llegado poco antes a su cumbre del creador. Ya los títulos de algunas composiciones - Hortus deliciarum", "Paradisiaca" - avisan del liberado arrimo al "Poema paradisiaco" de 1983". 5

Trataré ahora de precisar contrastivamente, a partir de los textos mencionados, en qué consisten estilísticamente ciertas afinidades esbozadas por la escritora argentina y, dentro de ellas, cuáles son las variantes lugonianas más significativas:

\section{1) 'D'Annunzio}

...l'immensa ombra del ciel prolunga i tuoi capelli in una sola forma, in una sola onda, in un solo fiume... ${ }^{6}$

\section{Lugones}

Sus lóbregos cabellos de pluviosa finura anochecian la hora de la fugaz aventura... ${ }^{7}$

Elementos idénticos: "capelli"'."cabellos".

Elementos equivalentes: "ombra del ciel"'-"anochecían"'; “onda"." "pluviosa".

Lo umbrátil dannunziano ("ombra') se transfiere, en Lugones, del cielo a los cabellos ("lóbregos") por un procedimiento de concreción, mientras que la metáfora de la "onda"' (movimiento ondulatorio del agua) y del río (movimiento lineal), referida a los cabellos, se convierte en la de "pluviosa finura" (los cabellos de aquella mujer son finos, como llovizna) por un procedimiento contrario de abstracción. La imagen del crepúsculo (la oscuridad inminente) contenida en " 1 ' immensa ombra del ciel", se simplifica, se esencializa en "anochecían", a la vez que, en el contexto general, se produce la inversión (amén de la abstracción)

${ }^{4}$ Cf. ibid., p. 135.

${ }^{5}$ Ibid., p. 138.

${ }^{6}$ Gabrielle D'Annunzio, "La sera", II, en Poema paradisiaco. Odi Navali (1891-1893), Treves, Milano, 1925, p. 63, apud Marani, op. cit., p. 141. También las referencias bibliográficas de los demás pasajes pueden hallarse completos en MARANI, passim. A partir de aquí indico Poema paradisiaco con la sigla PP.

7 Leopoldo Lugones, "Los cuatro amores de Dryops", en Los crepúsculos del jardín, Arnaldo Moen y Hermano, Buenos Aires, 1905, pp. 126-127. A partir de aquí indico Los crepúsculos del jardín con la sigla $L C D J$. 
de la imagen, puesto que en D'Annunzio es la sombra del cielo la que ensombrece los cabellos mientras que en Lugones es lo oscuro ("lóbregos") de los cabellos lo que oscurece la hora. Agréguese que Lugones elimina la reiteración triádica, retórica y solemne de D'Annunzio: "una sola forma / una sola onda / un solo fiume"' (actitud antirretórica).

\section{2) D'Annunzio}

Socchiusa è la finestra, sul giardino Un'ora passa lenta, sonnolenta...8
Lugones

Dormia la arboleda; las ventanas llenábanse de luz como pupilas...9

Elementos idénticos: "finestra"'-"ventana".

Elementos equivalentes: "giardino"'“"arboleda"; "sonnolenta""dormía".

Elementos análogos: "socchiusa"' [entreabierta]-"pupilas". La "finestra" por la que entra la luz ("socchiusa") se convierte en "pupila" del ojo, que también se entreabre para dejar pasar la luz: conversión de la imagen de la ventana, objeto inanimado, en la de la pupila del hombre, animada y abierta, ella también, hacia la luz (lirización de la imagen). A la vez, la imagen del sueño ("sonnolenta") se transfiere del tiempo ("ora") al espacio ("arboleda") con atenuación de la metáfora (desmetaforización) mientras se pierde, en lo fonoestilístico, la armonía imitativa y la rima interna de "lenta-sonnolenta" (simplificación).

\section{3) D'Annunzio}

...tu che non ridi al verso che ti loda e scuoti il capo... ${ }^{10}$
Lugones

...y mi palabra, en $t i$, sólo despierta una vaga sonrisa... ${ }^{11}$

Elementos equivalentes "tu"-"ti"; "ridi" -"sonrisa"; "loda""palabra". La imagen negativa del no-reírse y el incrédulo cabecear ante la palabra laudatoria (el "verso che ti loda") se transforma, a lo positivo, en "sonrisa" (inversión de la imagen); e "il verso che ti loda" en "palabra" (simplificación-esencialización). La "sonrisa", a su vez, que se connota líricamente mediante la su-

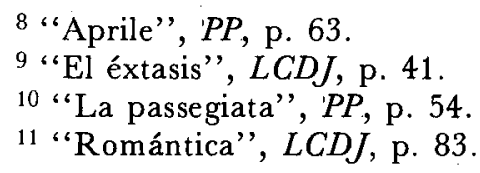


gestiva adjetivación "vaga" (lirización) substituye el gesto dannuziano del cabeceo (cancelación de la gestualidad-teatralidad-dramaticidad).

4) 'D'Annunzio

Il bel giardino in tempi assai lontani occultamente pare lontanare. . 12

\section{Lugones}

En la umbrosa avenida que se aleja hacia quién sabe qué misterio... ${ }^{13}$

Elementos idénticos: "lontanare" [forma poética por allontanarsi]-"se aleja".

Elementos equivalentes: "bel giardino"'-"umbrosa avenida".

Elementos análogos: "occultamente"-"misterio".

En Lugones la imagen genérica del italiano "bel" se especifica por lo umbroso (la belleza de aquella avenida es justamente la de ser "umbrosa"). A la vez, la escueta y seca imagen del italiano "occultamente" se hace más lírica al adquirir la connotación de misteriosa: "hacia quién sabe qué misterio"' (lirización).

5) 'D'Annunzio

Un cigno con remeggio lento fende il lago pura imagine del cielo.. e fluttua nel lene solco il velo de l'antica Tindaride, risplende su l'acque... ${ }^{14}$

\section{Lugones}

Cuando de pronto, con ligero arranque en su blancura casi refulgente el solitario cisne del estanque boga hacia ellas armoniosamente... ${ }^{15}$

Elementos idénticos: "cigno"'_"cisne"; "lago"'_"estanque".

Elementos equivalentes: "pura"'-"blancura"; "risplende"'-"refulgente", "fende",-"boga".

Elementos análogos: "con remeggio lento"'-"con ligero arranque"'-"fluttua nel lene solco" -"boga. .. armoniosamente".

El cisne dannunziano cruza el lago remando lentamente ("con remeggio lento"), mientras que el cisne lugoniano boga "con ligero arranque"'; lo cual representa una inversión dinámica: en D’Annunzio el remar es lento; en Lugones rápido. El "rispiende" ("resplandece"') dannunziano se convierte en el participioadjetivo "refulgente". El ritmo se "fluttua nel lene solco"' es aludido apenas en la correspondiente euritmia de "boga armoniosa-

\footnotetext{
12 “Hortus larvarum", PP, p. 57.

13 "Ave Maria gratia plena", $L C D J$, p. 183.

14 "'Hortus conclusus", $P P$, p. 27.

15 "Cisnes negros", $L C D J$, p. 16.
} 
mente". A su vez, desaparece la referencia clásica ("il velo de l'antica Tindaride").

6) D'Annunzio

Non è che voce d'acque su la pietra... non altro s'ode, ne la luce spenta, che quella voce che giù si lamenta, che si lamenta in fondo a quel giardino. . . ${ }^{16}$
Lugones

Las nobles fuentes que el jardin decoran gimen en la abismada lejanía, con esos balbuceos que ya lloran y que no son palabras todavía... ${ }^{17}$

Elementos idénticos: "giardino"-“"jardín".

Elementos equivalentes: "voce"'-"palabras"; "acque"_"fuentes"; "si lamenta".-"gimen"; "in fondo"." abismada".

El tema básico es el mismo: el quejido de las aguas que se oyen en el jardín; pero la dannunziana voz que se queja se convierte, para Lugones, en balbuceos que lloran sin ser palabras todavia (procedimiento de especificación: "voce"> "balbuceo"), y "si lamenta in fondo a quel giardino" se transfigura en "gimen en la abismada lejanía" (de lo concreto a lo abstracto y, de lo específico a lo genérico). A su vez, desaparece aquí también la reiteración enfática "si lamenta... si lamenta" (actitud antirretórica y antidramática).

7) D’Annunzio

Sul ciglio del marmoreo bacino che $\mathrm{i}$ misteri dell'acqua in sè racchiude la vergine giacente un suo divino sonno compone... ${ }^{18}$

\section{Lugones}

... en su serenidad inconmovida de claro mármol, sonrió dormida junto al agua la náyade yacente. . ${ }^{19}$

Elementos idénticos: "'marmoreo"'“"mármol"; "acqua"_"agua"; "vergine giacente"." náyade yacente".

Elementos equivalentes: "sonno"." dormida".

Elementos análogos: "(un suo divino sonno) compone"-"(su serenidad) inconmovida".

Mármol, agua, náyade yacente, sueño, inconmovida. . . aquí los materiales léxicos e icónicos se acumulan con especial intensidad. En el lugoniano "náyade yacente", en donde se mantiene el participio dannunziano "giacente", de tipo latino e insólito en el es-

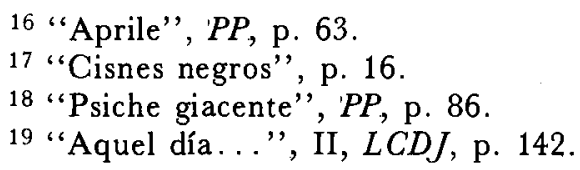


pañol, se produce, dentro de la especificación, la mitologización de la imagen: la virgen se convierte en "náyade" (agregación de la referencia clásica).

8) D'Annunzio

Or cosi fu; pe'l bosco andammo $[\ldots]$

Allora fu una molle cascata di viole ne l'aria: un solco d'oro s'apriva basso... ${ }^{20}$
Lugones

Calló por fin el mar, y asífue el caso [...]

En un largo suspiro de violeta se extenuaba de amor la tarde quieta... La palidez dorada del ocaso. . . ${ }^{21}$

Elementos idénticos: "Or cosí fu" -"y así fue el caso"; "viole”"violetas".

Elementos equivalentes: "soleo d'oro [.. ] basso"'-"palidez dorada del ocaso"'.

Elementos análogos: "una molle cascata"'-"un largo suspiro"; "l'aria" '“"la tarde quieta"'; y agréguese la analogía de la sensualidad, dentro de la misma zona semántica, entre el cit. "molle", y "extenuaba".

En "cosí fu" / "así fue" volvemos a encontrar la inversión (aquí meramente sintáctica). En "soleo d'oro basso" / "palidez dorada del ocaso" la abstracción. En " molle cascata" / "largo suspiro" la lirización y en "l'aria" / "la tarde quieta" de nuevo la abstracción.

Por el análisis de estas escuetas muestras que, por supuesto, habrá que ampliar, si se quierde alcanzar un mayor grado de aproximación crítica, y que se limitan a textos en verso (de la prosa me ocuparé en otra oportunidad), ya puede confirmarse que Alma Novella Marani no anduvo desacertada al cotejar los mencionados "rastros" y "resonancias". Aunque algunos puedan parecer casuales, otros resultan lo bastante consistentes como para confirmar en el argentino una operante memoria poética del vate italiano. Memoria poética, desde luego, y no simple imitación: Lugones, al utilizar ciertos materiales icónicos, léxicos y sonoros de D'Annunzio, los ha reinventado poéticamente, los ha concentrado y mezclado, sin perder nada de su originalidad, volviéndolos a combinar a su manera, en una especie de caleidoscopio.

20 "Peccato di maggio", en Intermezzo di rime, Bietri, Milano, 1908, p. 78.

21 "Tentación”, LCDJ, p. 29. 
Veamos ahora, a grandes rasgos, si es posible (aunque sea provisionalmente) deducir, de los materiales examinados, alguna tendencia general en lo que respecta a la actitud de Lugones frente al modelo dannunziano.

Ante todo descartamos metódicamente aquellos procedimientos estilísticos que pueden considerarse ambiguos en el sentido de que se presentan alternando con sus contrarios dentro de las muestras analizadas (y, por lo tanto, se neutralizan recíprocamente a los efectos sintomáticos). Es el caso de la concreción que alterna con la abstracción (núms. 1 y 8$)^{22}$ o de los estilemas alternantes especificación / generalización (núms. 4-6) supresión de referencias clásicas / agregación de referencias clásicas (núms. 5-7). Por lo demás, el argentino se diferencia del italiano utilizando, a veces, recursos meramente formales como la inversión (núms. 1-3-5-8), a veces recursos sustanciales como la simplificación o esencialización o atenuación de las imágenes (núms. 1-2-3) o junto con la cancelación de la gestualidadteatralidad (núm. 3) y, en lo estilístico; supresión de aquella reiteración enfática que bien caracteriza lo retórico y lo dramático dannunziano (núms. 1 y 6). En su lugar, aparece, acá y allá, la lirización de las imágenes (núms. 4-8).

Ahora bien, si procedimientos formales como la inversión sólo nos revelan la intención diferenciadora del poeta frente al modelo, los demás pueden ser síntomas de una actitud estilística (espiritual) de fondo, una actitud esencialmente antidramática y antirretórica; lo cual puede relacionarse coherentemente (sin necesidad de pensar en un "gesto fingido" como lo insinúa la prof. Marani, p. 141) con la mencionada actitud de "desdén" hacia D'Annunzio que, según recordó la misma Marani (p. 131), Lugones calificó de "¡retórico infranqueable en prosa [...] poeta precioso de la retórica decadente!"'. No habría, pues, contradicción real entre dicha actitud y la objetiva influencia que la crítica ha señalado puesto que, si bien Lugones no deja de utilizar ciertos materiales léxicos, icónicos o sonoros dannunzianos, con todo tiende a mantener, en su quehacer poético, tal declarada posición antirretórica y antidramática y, por ende, antidannunziana. Se puede decir, sintéticamente, que, en los pasajes señalados, Lugones tiende a atenuar, a filtrar y depurar y, de todos modos, a simplificar cierto verboso y dramático estilo dannunziano, tratando de convertir lo retórico en lírico. Pero habrá que ampliar la investi-

${ }^{22}$ Los números entre paréntesis se refieren a los párrafos correspondientes en este trabajo. 
gación al respecto, extendiendo el análisis también a los textos prosados.

En fin, estas notas aspiran a ser tan sólo metódicas y problemáticas. Se basan en el convencimiento de que una lectura contrastiva, mediante un cotejo analítico entre los dos autores, puede facilitar, entre otras cosas, la percepción más detallada de las distintas elecciones y procedimientos estilísticos de ambos, estimulando también la percepción de su proceso creativo y convirtiéndose, pues, en lectura crítica: crítica estilística.

Giovanni Meo-Zilio

Universidad de Venecia 